\title{
Hepatobiliary Manifestations and Complications in Inflammatory Bowel Disease: A Review
}

\author{
Fotios S. Fousekis ${ }^{\mathrm{a}}$, Vasileios I. Theopistos ${ }^{\mathrm{a}}$, Konstantinos H. Katsanos ${ }^{\mathrm{a}}$, \\ Epameinondas V. Tsianos ${ }^{\text {a }}$, Dimitrios K. Christodoulou ${ }^{\mathrm{a}, \mathrm{b}}$
}

\begin{abstract}
Liver and biliary track diseases are common extraintestinal manifestations of inflammatory bowel disease (IBD), reported both in Crohn's disease and ulcerative colitis, and may occur at any time during the natural course of the disease. Their etiology is mainly related to pathophysiological changes induced by IBD, and secondary, due to drugs used in IBD. Fatty liver is considered as the most frequent hepatobiliary manifestation in IBD, while primary sclerosing cholangitis (PSC) is the most correlated hepatobiliary disorder and is more prevalent in patients with ulcerative colitis. PSC can cause serious complications from the liver, biliary tree, and gallbladder and can lead to liver failure. Less frequently, IBD-associated hepatobiliary manifestations include cholelithiasis, granulomatous hepatitis, portal vein thrombosis, IgG4related cholangiopathy, pyogenic liver abscess, hepatic amyloidosis and primary biliary cirrhosis. Most of the drugs used for IBD treatment may cause liver toxicity. Methotrexate and thiopurines carry the higher risk for hepatotoxicity, and in many cases, dose adjustment may normalize the liver biochemical tests. Reactivation of hepatitis B and $\mathrm{C}$ virus during immunosuppressive use, especially during use of biological agents, is a major concern, and adequate screening, vaccination and prophylactic treatment is warranted.
\end{abstract}

Keywords: Primary sclerosing cholangitis; Hepatotoxicity; Hepatitis B; Hepatitis C; Extraintestinal manifestations

\section{Introduction}

Inflammatory bowel disease (IBD) is characterized by idiopathic chronic or recurring immune activation and inflammation of the gastrointestinal tract. Ulcerative colitis (UC) and Crohn's disease (CD) are the two major forms of IBD. Being a multisystemic disease, it can affect many organ systems and extraintestinal

Manuscript submitted February 17, 2018, accepted March 12, 2018

aDepartment of Gastroenterology and Hepatology, Medical School of Ioannina, Greece

${ }^{b}$ Corresponding Author: Dimitrios K. Christodoulou, Faculty of Medicine, Department of Gastroenterology and Hepatology, University of Ioannina, Ioannina 45100, Greece. Email: dchristodoulou@gmail.com

doi: https://doi.org/10.14740/gr990w manifestations are reported in more than one-third of patients with IBD [1]. A varied heterogenous group of hepatobiliary manifestations has been reported in both UC and CD [2] and approximately $5 \%$ of adults with IBD have developed chronic liver disease [3]. The pathogenesis of IBD-associated liver disorders is unclear. Immunological, genetic and environmental factors may contribute to the pathogenesis and correlation between IBD and hepatobiliary manifestations [4]. The most associated hepatobiliary manifestation is primary sclerosing cholangitis (PSC), particularly in UC. Other less frequent IBD-associated hepatobiliary disorders include cholelithiasis, steatosis, hepatic amyloidosis, granulomatous hepatitis, portal vein thrombosis, liver abscess and primary biliary cirrhosis (PBC). The main goal of this review is to summarize and analyze the most common hepatobiliary diseases and their complications in IBD, as well as drug-induced hepatotoxicity of IBD treatment.

\section{PSC}

PSC is a chronic, progressive disease, of unknown etiology of the intra- and extra-hepatic bile ducts and causes fibrosclerotic stenoses and destruction of bile ducts.

\section{Epidemiology}

PSC is closely associated with IBD, mainly with UC. In the Caucasian population, it is estimated that approximately $4 \%$ of patients with UC may develop PSC [5] and three-quarters of patients with PSC have UC [6]. PSC occurs in middle age with a 2:1 male predominance. In western countries, the estimated incidence rate of PSC is 0.77 per $10^{5}$ person-years and the prevalence is 8.5 to 13.6 per $10^{5}$ persons $[7,8]$.

\section{Complications}

PSC can lead to many complications from liver and biliary tree such as cirrhosis, hepatic failure and portal hypertension (Table 1) [9]. In addition, patients with PSC have an increased risk of developing cholangiocarcinoma (CCA) (the risk of CCA after 10 years is $9 \%$ [10]) and cholangitis [11]. CCA is frequently diagnosed within the first $1-3$ years after diagnosis of PSC and patients of advanced age at diagnosis have an increased incidence rate compared with younger patients $[12,13]$. Addition- 
Table 1. Complications of Primary Sclerosing Cholangitis

\begin{tabular}{ll}
\hline Liver & Cirrhosis, hepatic failure, portal hypertension \\
\hline Biliary tree & Cholangiocarcinoma, cholangitis \\
Gallbladder & Gallstones, cholecystitis, gallbladder carcinoma \\
Intestinal & Colorectal cancer, pouchitis \\
\hline
\end{tabular}

ally, the likelihood of developing colorectal cancer is increased in patients with IBD and PSC compared to people with IBD alone (odds ratio (OR): 4.79; 95\% confidence interval (CI): 3.58 - 6.41) [14] and colorectal cancer risk remains even after liver transplantation. In a meta-analysis, it was estimated that the incidence rate of colorectal cancer after liver transplantation is 5.8 per 1,000 person-years [15]. Therefore, surveillance colonoscopy, with random biopsies at 1 - 2 years intervals from the time of diagnosis of PSC, is recommended [16]. Moreover, gallbladder diseases are common in PSC patients. In an early study of 286 PSC patients, gallbladder abnormalities were found in $41 \%$ of patients. Gallstones, cholecystitis and gallbladder mass lesion were found in $25 \%, 25 \%$ and $6 \%$, respectively. Among patients with gallbladder mass lesion, $56 \%$ proved to be a gallbladder carcinoma. In patients with PSC, cholecystectomy is recommended if a gallbladder mass lesion is detected [17].

\section{IBD associated with PSC}

It seems that PSC affects the activity and location of IBD, and PSC is associated with more extensive (pancolitis and backwash ileitis) but less active UC, with a lower rate of colectomy $[18,19]$, while proctocolectomy does not appear to have an effect on PSC course [20]. The most common localizations of PSC-CD are colitis and ileocolitis [21]. Furthermore, in patients with UC and ileal pouch-anal anastomosis, PSC is a risk factor of pouchitis and the increased risk persists even after liver transplantation $[22,23]$.

\section{Etiology}

PSC is unclear. Several hypotheses have been proposed, such as chronic portal bacteremia, alterations in the gut microbiota, unrecognized chronic viral infections and genetic abnormalities of immunoregulation or bile transport [24]. Genetic factors may play a determinant role, as there is familial occurrence of PSC and UC. In particular, the coexistence of both diseases in twins shows that there are mutual responsible genes between UC and PSC $[25,26]$. Multiple genetic factors of susceptibility have been reported, such as HLADRB1*0301 (DR3), HLAB8 and HLADRB3*0101 (DRw52a) [27].

\section{Clinical presentation and diagnosis}

PSC should be considered in patients with IBD, particularly UC, with abnormal liver markers. Clinical presentation is varied and most patients with PSC are asymptomatic at diagnosis. In symp- tomatic patients, right upper quadrant abdominal discomfort, pruritus, fatigue and weight loss are common. Also, in approximately half of these patients, hepatomegaly, splenomegaly and jaundice are the most frequent clinical findings. The diagnosis of PSC is a combination of biochemical profile and cholangiography. Biochemical markers show cholestasis. Specifically, alkaline phosphatase (ALP) is elevated and is the most frequent biochemical abnormality. However, ALP in the normal range does not exclude PSC. Serum aminotransferase levels are usually increased [28]. Additionally, a variety of autoantibodies have been detected in PSC such as anti-nuclear antibodies (ANAs), smooth muscle antibodies (SMAs) and anti-perinuclear antibody (pANCA) in $24-53 \%, 13-20 \%$ and $65-88 \%$ of patients, respectively [29]. Cholangiography shows characteristic bile duct changes, such as strictures and dilations of intra- and extra-hepatic bile ducts. Endoscopic retrograde cholangiopancreatography (ERCP) is a more accurate diagnostic method than magnetic resonance cholangiography (MRCP), but MRCP is used more frequently because ERCP may be associated with serious complications, such as pancreatitis and bacterial cholangitis [30]. However, cholangiography may be normal to small duct PSC.

\section{Treatment}

Treatment of PSC is limited and the goals of treatment are the control of symptoms and the management of complications, such as variceal bleeding. The use of ursodeoxycholic acid (UDCA) was proposed as treatment for PSC. However, clinical trials showed that UDCA is associated with improvement in serum liver markers but does not improve the patients' survival, liver histology, prevention of CCA or improvement of clinical symptoms [31]. Also, a meta-analysis shows that UDCA does not decrease the risk of adenomas or colon cancer in patients with UC and PSC [32]. Furthermore, infliximab [33], budesonide [34], ciclosporin and azathioprine (AZA) [35] are ineffective. Patients with end-stage liver disease are indicated for liver transplantation, which is the only effective treatment for these patients and the survival rates at 5 and 10 years are approximately $85 \%$ and $70 \%$, respectively. The incidence of recurrent $\mathrm{PSC}$ is $20 \%$ [36].

\section{Prognosis}

The prognosis of PSC is variable and the median reported survival from the time of diagnosis until death or liver transplantation is 12 - 18 years [37]. It seems that the outcome of PSC with concomitant CD is more benign than PSC with UC or without UC [38]. Mayo risk score can be used to estimate the survival of people with PSC and it is based on age, total bilirubin, albumin, aspartate aminotransferase and history of variceal bleeding [39].

\section{Small Duct PSC}

Small duct PSC is characterized by typical cholestatic and his- 
tological features of PSC (periductal concentric fibrosis "onion-skin"), whereas normal bile ducts in the cholangiography. Liver biopsy is recommended for the diagnosis of small duct PSC [40]. Of the patients, $88 \%$ with small duct PSC have concomitant IBD and mainly UC [41]. However, small duct PSC is more common among $\mathrm{CD}$ patients $(22 \%$ of PSC-CD patients vs. $6 \%$ of PSC-UC patients) [42] and presents a better longterm prognosis as compared with large duct PSC. The patients with small duct PSC have longer transplantation free survival compared with large duct PSC patients (13 vs. 10 years). Additional, $22 \%$ of small duct PSC may progress to large duct PSC within 8 years and it seems that patients with small duct PSC do not develop CCA, unless small duct PSC progresses to large duct PSC [43].

\section{Autoimmune Hepatitis (AIH)/PSC Overlap Syn- drome}

AIH/PSC overlap syndrome is an uncommon subtype in patients having clinical, biochemical, serological and/or histological overlap findings of PSC and AIH. AIH/PSC overlap syndrome has been reported in patients with IBD, especially with UC. There is high suspicion in patients with PSC who have auto-antibodies, relatively low ALP and interface hepatitis in liver biopsy [44]. AIH/PSC syndrome is more frequent in childhood population and prognosis may be better, as compared to PSC alone. Treatment with corticosteroids is recommended [45].

\section{IgG4-Associated Cholangiopathy (IAC)}

IAC belongs to a multisystem fibroinflammatory disorder (IgG4-related disease) that affects many organ systems. The most common symptom is bile duct obstruction and jaundice. The diagnosis of IAC relies on elevated serum IgG4 levels ( $>$ $135 \mathrm{mg} / \mathrm{dL}$ ) and histopathologic findings ( $>10$ IgG4-positive plasma cells per high-power field) [46]. An increased IgG4 level has been observed in $9 \%$ of patients with PSC [47]. Cholangiography alone does not separate IAC from PSC and CCA [48]. IAC has been reported in patients with concomitant $\mathrm{UC}$ or $\mathrm{CD}[49,50]$. IAC responds to corticosteroid therapy, although relapse occurs in more than $40 \%$ of patients [51]. Immunodulators can be useful for maintenance [52].

\section{Cholelithiasis}

Cholelithiasis is another manifestation in patients with IBD. People with CD have double the risk for the development of gallstones. Contrary, patients with UC have no increased risk [53]. Prevalence of cholelithiasis in CD ranges from $11 \%$ to $34 \%$, while in general population, it ranges from $5.5 \%$ to $15 \%$ [54]. Many independent parameters of CD have been related with cholelithiasis and include ileo-colonic CD location, disease duration ( $>15$ years), extent of ileal resection $(>30 \mathrm{~cm})$, long hospital stay, number of hospitalizations $(>3)$, multiple total parenteral nutrition treatments, lifetime surgery and frequency of clinical recurrences $(>3)$ [55]. Gallstones are mainly caused by malabsorption of bile salts, which interferes with enterohepatic circulation and causes elevation of enterohepatic circulation and gallstones development. Also, incomplete emptying or prolonged contraction time of the gallbladder does not seem to cause gallstone formation in CD [56], but increased concentration of cholesterol in gallstones after ileoanal anastomosis has been reported [57]. However, an analysis of bile composition in patients with ileal resection due to $\mathrm{CD}$ showed that cholesterol saturation is lower in CD patients. Thus, it seems that these patients do not run an increased risk of cholesterol gallstone formation [58]. Complications of cholelithiasis may be an indication for cholocystectomy. A multivariate analysis showed that the presence of concomitant IBD was independently associated with a significantly increased risk $(\mathrm{OR}=4.64)$ for postoperative complications [59]. However, synchronous prophylactic cholecystectomy during ileocolonic resection for $\mathrm{CD}$ ileitis is not recommended [60].

\section{Non-Alcoholic Fatty Liver Disease (NAFLD)}

NAFLD is a syndrome and its diagnosis requires evidence of hepatic steatosis either by imaging or by histology (liver biopsy) and exclusion of secondary causes of steatosis such as use of steatogenic drugs (e.g., amiodarone, methotrexate, and corticosteroids) or excessive alcohol consumption [61]. Steatosis or fatty liver disease has been described in up to $50 \%$ of pathological liver biopsies in IBD patients [62]. What is more, in a study of 511 subjects with the utilization of ultrasound, liver steatosis was found in approximately $40 \%$ of IBD patients, but two-thirds of the patients have been receiving corticosteroids, a factor that has been associated with the development of steatosis [63]. On the other hand, in another study with 928 IBD patients, NAFLD was reported in $8.2 \%$ of IBD population. The diagnosis of NAFLD was made with imaging. When IBD patients with NAFLD were compared with IBD patients who had no evidence of NAFLD, the analysis showed that NAFLD patients were older and had a later onset of IBD. Also, NAFLD was less frequent in patients receiving anti-TNF-a therapy. In trials on animal models for NAFLD, the treatment with antibodies against TNF improved liver histology and decreased serum alanine aminotransferase (ALT) [64]. In addition, similar trials showed that infliximab not only leads to reduction of steatosis and fibrosis but also to the improvement of insulin action [65]. Furthermore, it has been reported that IBD patients develop NAFLD with fewer metabolic risk factors than nonIBD patients with NAFLD. In a multivariate analysis, hypertension $(\mathrm{OR}=3.5)$, obesity $(\mathrm{OR}=2.1)$, small bowel surgeries $(\mathrm{OR}=3.7)$ and use of steroids at the time of imaging $(\mathrm{OR}=$ 3.7) were independent factors associated with NAFLD [66].

\section{Pyogenic Liver Abscess}

Liver abscess is a rare extraintestinal complication of IBD, mainly CD. The incidence of liver abscess in patients with $C D$ 
is higher than in people in the general population $(114$ - 297 per 100,000 versus 8 - 16 per 100,000). Furthermore, patients with $\mathrm{CD}$ and liver abscess are younger and present more frequently multiple liver abscesses than solitary liver abscess compared with patients with liver abscess in general population [67]. Clinical and laboratory findings of disease are not specific and can imitate the exacerbation of CD. For this reason, diagnosis may be delayed. It is diagnosed by imaging and treatment includes administration of antibiotics and if required, surgical or percutaneous drainage (CT or ultrasound-guided) [68]. The mechanism of liver abscesses development is not well-known. Diabetes mellitus, endoscopic insertion of biliary drainage, abdominal surgery, long-term treatment with steroids, fistulizing disease, intra-abdominal abscesses and malnutrition are probable predisposing factors to developing liver abscess. The latter may also be caused due to direct extension of intra-abdominal abscess or pyemia in the portal system and extension to the liver $[69,70]$. Also, liver abscesses can be caused by enterohepatic fistula [71].

\section{Granulomatous Hepatitis}

Granulomatous hepatitis is another rare hepatic manifestation of CD. Granulomas are typically asymptomatic and even extensive disease causes minor hepatomegaly and little or no jaundice. Diagnosis is based on liver biopsy. The main manifestations are unexplained hepatic masses during imaging tests or asymptomatic elevations of cholestatic enzymes [72]. Granulomas on liver histology in patients with IBD are described in less than $1 \%$ and can be an extraintestinal manifestation of IBD or have infectious or malignant etiologies [73, 74]. Mesalamine and sulfasalazine can induce granulomatous hepatitis $[75,76]$, while a case with granulomatous hepatitis secondary to histoplasma capsulatum infection after treatment with infliximab has been reported [77].

\section{Hepatic Amyloidosis}

Secondary systemic amyloidosis is a complication of chronic inflammatory disorders and occurs in less than $1 \%$ in IBD, more often in CD than in UC (0.9-3\% vs. 0.07\%) [54]. In IBD, amyloidosis is more frequent in males and the mean age of diagnosis is 40 years. In patients with $\mathrm{CD}$, amyloidosis is associated 4.4 times more frequently with $\mathrm{CD}$ of the colon than with pure small bowel disease and it seems that there is no correlation between extraintestinal manifestations and development of amyloid. Hepatic amyloidosis may present asymptomatic hepatomegaly. Treatment in these patients is to control the underlying IBD and thereby, decrease the release of the acute phase reactant serum amyloid A. In two cases with systematic amyloidosis and UC, colchicine has been tried with rapid and prolonged benefits for these patients [78]. Also, two patients with CD were treated with anti-TNF drugs, showing a clinical improvement of their amyloidosis [79]. It has been suggested that anti-TNF factors not only reduce the synthesis of amyloid precursors but can also decrease the formation of amyloid depositions [80].

\section{PBC}

IBD, particularly UC, can sometimes be accompanied by PBC. $\mathrm{PBC}$ is a chronic autoimmune liver disease, the etiology is unknown and the prevalence of $\mathrm{PBC}$ among patients with $\mathrm{UC}$ is higher than in general population. The diagnosis of $\mathrm{PBC}$ can be established when there are two of the following three criteria: 1) biochemical evidence of cholestasis; 2) presence of antimitochondrial antibodies (AMAs); 3) histologic evidence of non-suppurative destructive cholangitis and destruction of interlobular bile ducts. PBC is associated with various autoimmune diseases, such as Sjogren's syndrome, chronic thyroiditis and rheumatoid arthritis but rarely IBD [81]. Patients with $\mathrm{PBC}$ and $\mathrm{UC}$ are younger and more often males compared with classical PBC. Also, UC is usually mild and left-sided [82, 83].

\section{Budd-Chiari Syndrome}

Budd-Chiari syndrome is caused by hepatic venous thrombosis and several cases of patients with IBD, mainly with UC, have been reported. Patients with UC during a flare phase carry eight times higher the risk for thromboembolism [84].

\section{Portal Vein Thrombosis}

Vascular complications such as arterial and venous thromboembolisms during the course of IBD have been reported and according to a Mayo clinic study, thromboembolic complications develop in $1.3 \%$ IBD patients, with a mortality rate of $50 \%$ [85]. The prevalence of portal vein thrombosis in IBD is $0.17 \%$ [86]. The causes of portal vein thrombosis are manifold and include inflammation, immobilization, extent of colon disease, surgery, central catheters corticosteroids and smoking. Additionally, patients with IBD are associated with many coagulation abnormalities and have elevated factors V and VIII levels, platelet counts and fibrinogen levels, and/or decreased antithrombin III levels [62]. IBD may be an independent and disease-specific risk factor for thromboembolism [87]. Furthermore, as a retrospective study showed, portomesenteric vein thrombosis can occur when IBD is inactive and the diagnosis was fortuitous in $40 \%$ of cases in one study [88].

\section{Drug-Induced Hepatotoxicity}

\section{Corticosteroids}

Corticosteroids are commonly used in patients with IBD for inducing remission in $\mathrm{CD}$ and $\mathrm{UC}$ and can cause major side effects. The hepatic complications include hepatic enlargement, steatosis, induction or worsening non-alcoholic steatohepatitis [89]. These affects are rapidly reversed with withdrawal. 
Also, long-term use can result in reactivation or exacerbation of chronic viral hepatitis.

\section{Aminosalicates}

Aminosalicates are widely used in treatment of IBD and mainly in UC. It is extremely rare to cause hepatotoxicity, but some serious cases such as granulomatous hepatitis as a complication of sulfasalazine and fulminant hepatitis have been reported $[76,90]$. In clinical trials, hepatic biochemical abnormalities have been reported in $2 \%$ of UC patients treated with mesalazine [91]. From 1991 to 1998 according to the committee on the safety of medicines of the United Kingdom, the incidence of hepatitis was 3.2 and six cases per million of prescriptions for mesalazine and sulfasalazine, respectively. Also, there is stronger correlation between hepatotoxicity of sulfasalazine and rheumatoid arthritis (RA) than IBD, as the incidence of hepatotoxicity of sulfasalazine was 3.1 and 8.6 cases per million prescriptions in patients with only IBD or only RA, respectively [92].

\section{Methotrexate}

Methotrexate has been associated with hepatotoxicity through cumulative dose dependent mechanism and may cause steatosis, liver fibrosis and cirrhosis. Hence, liver biopsy was proposed before the initiation of treatment and a second biopsy later, after a cumulative dose of $1.5-2 \mathrm{~g}$. However, the recommendation was challenged, as the rate of liver disease that was found in patients with RA on methotrexate treatment was very low [93]. A meta-analysis of clinical trials showed that the rate of abnormal aminotransferase serum levels (defined as up to a two-fold elevation over the upper limit of the normal (ULN)) in patients treated with methotrexate for IBD was 1.4 per 100 person-months, while the incidence of hepatotoxicity (defined as greater than a two-fold over ULN) was 0.9 per 100 personmonths [94]. For prevention of liver damage, supplementation with folic acid is indicated, because folic acid has been correlated with reduction of methotrexate-induced hepatotoxicity [95]. Moreover in the pediatric population, a meta-analysis showed that $10.2 \%$ of children with IBD on methotrexate therapy presented abnormal liver biochemistry and $4.5 \%$ of children required withdrawal [96]. Obesity, alcohol and diabetes mellitus are considered risk factors for liver injury by methotrexate, and so, alcohol should be strictly avoided [97-99].

\section{Thiopurines: AZA and 6-mercaptopurine (MP)}

AZA and its metabolite 6-MP are immunodulattors that are frequently used in IBD. In the liver, AZA is metabolized by xanthine oxidase and thiopurine methyltransferase (TPMT). AZA and MP can induce liver injury and there are three possible mechanisms of hepatotoxicity: hypersensitivity, idiosyncratic reaction and endothelial cell injury. Hepatotoxicity includes mild and asymptomatic rises in serum aminotrans- ferases levels, acute cholestatic hepatitis, which develops in the first year of treatment, and chronic liver disease which is marked by peliosis and veno-occlusive disease, which usually develops 1 - 5 years after starting treatment [100]. Thiopurines metabolites levels such as 6-methylmercaptopurine (6-MMP) have been associated with pathogenesis of liver toxicity [101]. Retrospective studies showed that the prevalence of hepatotoxicity in patients with IBD was $3 \%$ and the mean annual drug-induced liver disorder was $1 \%$. However, a prospective study showed higher incidence, approximately 10\% [102]. What is more, according to a long-term follow-up study, the risk of hepatotoxicity is higher in males and in CD [103]. Furthermore, it seems that AZA-related hepatotoxicity is not associated with TPMT polymorphisms [104].

A very rare side effect is the nodular regenerative hyperplasia (NRH), which is characterized by widespread benign transformations of the hepatic parenchyma into small regenerative nodules, without annular fibrosis and can lead to non-cirrhotic portal hypertension. The male sex and stricturing behavior are associated with NRH in patients treated with AZA [105], while discontinuation of these medications extenuates portal hypertension within 1 year [106]. Additionally, an allopurinolthiopurine combination may be associated with $\mathrm{NRH}$ and the prevalence of NRH in patients with IBD, who are treated with allopurinol-thiopurine therapy, is 5\% [107]. Moreover, cases of AZA-induced veno-occlusive disease in patients with IBD have been reported [108, 109].

\section{Anti-tumor necrosis factor (TNF)-a agents}

Infiximab and adalimumab are chimeric and human monoclonal antibodies against TNF-a, respectively. These can rarely cause liver damage, most often infliximab. In a retrospective cohort, an ALT elevation ( $>60 \mathrm{U} / \mathrm{L}$ ) was reported in $6 \%$ of IBD patients upon the initiation of biological agents; however, in half of them, this could be linked to an alternative explanation [110]. Liver injury can occur irrespectively of the number of infusions or injections, dose or time. The anti-TNF-a agents can cause from mild transaminase elevation to acute hepatitis. Most times, hepatitis has autoimmune features with elevation of antinuclear, anti-smooth muscle and anti-double strand DNA antibodies. The mechanism of hepatotoxicity is unknown. In vitro trials showed that infliximab alone or in combination with AZA exerts no direct hepatotoxic effect on HepG2 cells [111]. It is recommended that treatment with infliximab can be used in patients with liver disease but should be avoided or discontinued in patients with transaminases more than three times the ULN [112]. The prognosis is favorable after drug withdrawal; however, one patient with preexisting cirrhosis developed liver failure and required liver transplantation. Patients may benefit from a course of corticosteroids. After cure of hepatitis, the patient can be treated with another biological agent without recurrence of hepatitis [113].

Golimumab is a human monoclonal antibody (anti-TNF) and can cause asymptomatic mild to moderate serum ALT elevation unaccompanied by jaundice. In clinical trials, the serum ALT elevation occurred in $6-8 \%$ of patients treated with golimumab versus $2.6-3 \%$ placebo-treated subjects $[114,115]$. 
Table 2. Hepatobiliary Complications in IBD

\begin{tabular}{lll}
\hline Hepatobiliary manifestations & Crohn's disease & Ulcerative colitis \\
\hline Primary sclerosing cholangitis & + & ++ \\
Fatty liver & + & + \\
Liver abscess & ++ & + \\
Granulomatous hepatitis & + & + \\
IgG4-related cholangiopathy & - & + \\
Gallstones & + & + \\
Hepatic amyloidosis & ++ & ++ \\
Primary biliary cirrhosis & + & + \\
Portal vein thrombosis & + & + \\
Reactivation chronic viral hepatitis & + & + \\
Drug-induced hepatotoxicity & + & + \\
\hline
\end{tabular}

(-): no association; (+): association; (++): more frequent than other type of IBD.

Certolizumab pegol is a pegylated humanized Fab fragment and has been associated with mild aminotransferase elevations similar to the rate found with placebo therapy [110].

Vedolizumab is a humanized monoclonal antibody to integrin $\alpha 4 \beta 7$ that inhibits adhesion and migration of leukocytes into the gastrointestinal tract and has been linked to a low rate of serum aminotransferase elevation during therapy [116, $117]$.

\section{Hepatosplenic T-cell lymphoma (HSTCL)}

HSTCL is a rare, aggressive and lethal extranodal form of non-Hodgkin's lymphoma with about 200 reported cases in the literature. Cases of HSTCL have been reported in patients treated with receiving AZA/6-MP and anti-TNF therapy. Most cases of HTSCL include patients treated with a combination of anti-TNF and thiopurine. However, there are cases of patients treated with AZA or MP alone [118]. Patients with IBD and HSTCL are frequently males ( $90 \%$ of the cases), younger than 35 years of age and having received AZA for over 2 years [119].

\section{Viral Hepatitis and IBD}

\section{Hepatitis B and IBD}

Hepatitis B infection is a global health problem. It was considered that the risk of hepatitis B virus (HBV) infection was increased in patients with IBD due to blood transfusions and surgical and/or endoscopic procedures. However, recent epidemiologic findings have changed this view. A Spanish multicenter study, which included 2,076 IBD patients, showed that the prevalence of HBV infection in IBD patients is similar to the general population. Present and/or past $\mathrm{HBV}$ infection was found in $8 \%$ and $7.1 \%$ of patients with UC and CD, respectively. Also, young age, family history of hepatitis and moderate to severe disease were associated with HBV [120]. During last decades, particularly after the development of biological agents, more and more IBD patients have been treated with immunosuppressive agents and have had an increased risk of HBV reactivation, notably at the time of withdrawal or tapering of immunosuppressive therapy [121]. A multicenter study assessed the risk of reactivation of HBV in IBD patients treated with immunosuppressants. Liver dysfunction was reported in nine out of $25 \mathrm{HBsAg}$-positive patients (36\%). It seemed that the use of two or more immunosuppressants was an independent predictor factor for reactivation of HBV. Also, it was observed that patients tested positive for HBV DNA and/or not receiving prophylactic therapy had greater risk of reactivation [122]. Thus, patients undergoing immunosuppressive therapy should take preventive measures. According to European Crohn's and Colitis Organization (ECCO) [123]: 1) Seronegative patients ( $\mathrm{HBsAg}$ and anti-HBc negative) should be vaccinated. However, it seems that response to vaccination (anti-HBs $>10 \mathrm{mIU} / \mathrm{mL})$ in IBD patients is poorer $(<$ $50 \%$ ) [124] than in healthy population (approximately 95\%). Multivariate analysis showed that serum albumin levels below $3.6 \mathrm{mg} / \mathrm{dL}$ at the beginning of vaccination, long-term IBD course and corticosteroid therapy are associated with weaker response to vaccination [125]. Furthermore, many IBD patients with protective anti-HBs titers lose them over time (18\% per patient years). The risk of losing protective anti-HBs titers is higher among patients who are treated with biological agents (hazard ratio $=3.1$ ) [126]. 2) In seropositive patients $(\mathrm{HBsAg}+)$ prophylactic treatment with nucleotide/ nucleoside analogues is recommended. 3) HBsAg-negative patients with anti-HBc positive should be monitored for elevation of transaminases.

\section{Hepatitis C and IBD}

Concurrent hepatitis $\mathrm{C}$ virus (HCV) infection in IBD patients seems to be uncommon. A collaborating Spanish multicenter study, which included 2,076 IBD patients, showed that the 
prevalence of present or past $\mathrm{HCV}$ infection in IBD patients is low, specifically $1.3 \%$ and $2.3 \%$ in patients with UC or CD, respectively [120]. In the past, patients with chronic hepatitis $\mathrm{C}$ infection and IBD could have specific problems, because the treatment of the one disease might affect the other disease and cause its exacerbation. However, this view is disputed. In a study with $15 \mathrm{HCV}$ and IBD patients treated with interferon, only one patient experienced an exacerbation of the disease during antiviral treatment [127]. Currently, the development of new agents for hepatitis $\mathrm{C}$ minimizes the impact on the course of IBD. As regards the effect of the immunosuppressive therapy of IBD in the course of hepatitis C, in a Spanish study, liver dysfunction was observed in $16 \%(8 / 51)$ of patients with IBD and positive HCV RNA. Seven patients were treated with steroids and one case with AZA [122]. Also, it seems that the use of infliximab in patients with HCV is safe. In a retrospective study, five patients who had concurrent HCV infection and IBD received anti-TNF factor (infliximab). Only one patient who had HIV co-infection had elevation of hepatic biochemical tests [128]. Nowadays, the complete cure of chronic hepatitis $\mathrm{C}$ with a 3-month antiviral treatment is recommended to avoid future problems in all patients and certainly in patients with IBD.

\section{Conclusion}

Hepatobiliary disorders are frequent extraintestinal manifestations of IBD or related diseases (Table 2) and abnormal liver biochemical tests are present in up to $30 \%$ of patients with IBD. They are varied and range from limited mild diseases to serious progressive life-threatening diseases. Therefore, patients with IBD should be periodically monitored by liver function tests and a full diagnostic workup is required when elevated liver enzymes are found. Differential diagnosis should always include drug-induced hepatotoxicity, although incidence of serious complications is low. In most cases of drug-induced hepatotoxicity, dose adjustment or discontinuation of the drug will result in improvement. The risk of reactivation of viral hepatitis B during immunosuppressants use imposes screening of patients before treatment and vaccination and chemoprevention, if required.

\section{Conflict of Interest}

None of the authors has any conflict of interest to report that may be related to this submission.

\section{Author Contributions}

All authors contributed equally.

\section{Funding}

No funding by any private or public party was received for this review.

\section{Abbreviations}

AZA: azathioprine; AIH: autoimmune hepatitis; CCA: cholangiocarcinoma; CD: Crohn's disease; IBD: inflammatory bowel disease; IAC: IgG4-associated cholangiopathy; HBV: hepatitis B virus; HCV: hepatitis C virus; HSTCL: hepatosplenic T-cell lymphoma; MP: mercaptopurine; NAFLD: non-alcoholic liver disease; PBC: primary biliary cirrhosis; PSC: primary sclerosing cholangitis; UC: ulcerative colitis

\section{References}

1. Ott C, Scholmerich J. Extraintestinal manifestations and complications in IBD. Nat Rev Gastroenterol Hepatol. 2013;10(10):585-595.

2. Yarur AJ, Czul F, Levy C. Hepatobiliary manifestations of inflammatory bowel disease. Inflamm Bowel Dis. 2014;20(9):1655-1667.

3. Mendes FD, Levy C, Enders FB, Loftus EV, Jr., Angulo P, Lindor KD. Abnormal hepatic biochemistries in patients with inflammatory bowel disease. Am J Gastroenterol. 2007;102(2):344-350.

4. Navaneethan U. Hepatobiliary manifestations of ulcerative colitis: an example of gut-liver crosstalk. Gastroenterol Rep (Oxf). 2014;2(3):193-200.

5. Olsson R, Danielsson A, Jarnerot G, Lindstrom E, Loof L, Rolny P, Ryden BO, et al. Prevalence of primary sclerosing cholangitis in patients with ulcerative colitis. Gastroenterology. 1991;100(5 Pt 1):1319-1323.

6. Wiesner RH, Grambsch PM, Dickson ER, Ludwig J, MacCarty RL, Hunter EB, Fleming TR, et al. Primary sclerosing cholangitis: natural history, prognostic factors and survival analysis. Hepatology. 1989;10(4):430-436.

7. Molodecky NA, Kareemi H, Parab R, Barkema HW, Quan H, Myers RP, Kaplan GG. Incidence of primary sclerosing cholangitis: a systematic review and metaanalysis. Hepatology. 2011;53(5):1590-1599.

8. Boberg KM, Aadland E, Jahnsen J, Raknerud N, Stiris M, Bell $\mathrm{H}$. Incidence and prevalence of primary biliary cirrhosis, primary sclerosing cholangitis, and autoimmune hepatitis in a Norwegian population. Scand J Gastroenterol. 1998;33(1):99-103.

9. Lee YM, Kaplan MM. Primary sclerosing cholangitis. N Engl J Med. 1995;332(14):924-933.

10. Claessen MM, Vleggaar FP, Tytgat KM, Siersema PD, van Buuren HR. High lifetime risk of cancer in primary sclerosing cholangitis. J Hepatol. 2009;50(1):158-164.

11. Goldberg DS, Camp A, Martinez-Camacho A, Forman L, Fortune B, Reddy KR. Risk of waitlist mortality in patients with primary sclerosing cholangitis and bacterial cholangitis. Liver Transpl. 2013;19(3):250-258.

12. Gidwaney NG, Pawa S, Das KM. Pathogenesis and clinical spectrum of primary sclerosing cholangitis. World J Gastroenterol. 2017;23(14):2459-2469.

13. Weismuller TJ, Trivedi PJ, Bergquist A, Imam M, Len- 
zen H, Ponsioen CY, Holm K, et al. Patient age, sex, and inflammatory bowel disease phenotype associate with course of primary sclerosing cholangitis. Gastroenterology. 2017;152(8):1975-1984 e11978.

14. Soetikno RM, Lin OS, Heidenreich PA, Young HS, Blackstone MO. Increased risk of colorectal neoplasia in patients with primary sclerosing cholangitis and ulcerative colitis: a meta-analysis. Gastrointest Endosc. 2002;56(1):48-54.

15. Singh S, Edakkanambeth Varayil J, Loftus EV, Jr., Talwalkar JA. Incidence of colorectal cancer after liver transplantation for primary sclerosing cholangitis: a systematic review and meta-analysis. Liver Transpl. 2013;19(12):1361-1369.

16. Wang R, Leong RW. Primary sclerosing cholangitis as an independent risk factor for colorectal cancer in the context of inflammatory bowel disease: a review of the literature. World J Gastroenterol. 2014;20(27):8783-8789.

17. Said K, Glaumann H, Bergquist A. Gallbladder disease in patients with primary sclerosing cholangitis. J Hepatol. 2008;48(4):598-605.

18. Joo M, Abreu-e-Lima P, Farraye F, Smith T, Swaroop P, Gardner L, Lauwers GY, et al. Pathologic features of ulcerative colitis in patients with primary sclerosing cholangitis: a case-control study. Am J Surg Pathol. 2009;33(6):854-862.

19. Navaneethan U, Venkatesh PG, Mukewar S, Lashner BA, Remzi FH, McCullough AJ, Kiran RP, et al. Progressive primary sclerosing cholangitis requiring liver transplantation is associated with reduced need for colectomy in patients with ulcerative colitis. Clin Gastroenterol Hepatol. 2012;10(5):540-546.

20. Cangemi JR, Wiesner RH, Beaver SJ, Ludwig J, MacCarty RL, Dozois RR, Zinsmeister AR, et al. Effect of proctocolectomy for chronic ulcerative colitis on the natural history of primary sclerosing cholangitis. Gastroenterology. 1989;96(3):790-794.

21. de Vries AB, Janse M, Blokzijl H, Weersma RK. Distinctive inflammatory bowel disease phenotype in primary sclerosing cholangitis. World J Gastroenterol. 2015;21(6):1956-1971.

22. Penna C, Dozois R, Tremaine W, Sandborn W, LaRusso N, Schleck C, Ilstrup D. Pouchitis after ileal pouch-anal anastomosis for ulcerative colitis occurs with increased frequency in patients with associated primary sclerosing cholangitis. Gut. 1996;38(2):234-239.

23. Mathis KL, Dozois EJ, Larson DW, Cima RR, Sarmiento JM, Wolff BG, Heimbach JK, et al. Ileal pouch-anal anastomosis and liver transplantation for ulcerative colitis complicated by primary sclerosing cholangitis. Br J Surg. 2008;95(7):882-886.

24. Restellini S, Chazouilleres O, Frossard JL. Hepatic manifestations of inflammatory bowel diseases. Liver Int. 2017;37(4):475-489.

25. Habior A, Rawa T, Orlowska J, Sankowska M, Lewartowska A, Tilszer A, Pawlak J, et al. Association of primary sclerosing cholangitis, ulcerative colitis and coeliac disease in female siblings. Eur J Gastroenterol Hepatol. 2002;14(7):787-791.
26. Quigley EM, LaRusso NF, Ludwig J, MacSween RN, Birnie GG, Watkinson G. Familial occurrence of primary sclerosing cholangitis and ulcerative colitis. Gastroenterology. 1983;85(5):1160-1165.

27. Karlsen TH, Schrumpf E, Boberg KM. Genetic epidemiology of primary sclerosing cholangitis. World J Gastroenterol. 2007;13(41):5421-5431.

28. Karlsen TH, Schrumpf E, Boberg KM. Primary sclerosing cholangitis. Best Pract Res Clin Gastroenterol. 2010;24(5):655-666.

29. Uko V, Thangada S, Radhakrishnan K. Liver disorders in inflammatory bowel disease. Gastroenterol Res Pract. 2012;2012:642923.

30. Enns R. The Use of ERCP Versus MRCP in Primary Sclerosing Cholangitis. Gastroenterol Hepatol (N Y). 2008;4(12):852-854.

31. Othman MO, Dunkelberg J, Roy PK. Urosdeoxycholic acid in primary sclerosing cholangitis: a meta-analysis and systematic review. Arab J Gastroenterol. 2012;13(3):103110.

32. Ashraf I, Choudhary A, Arif M, Matteson ML, Hammad HT, Puli SR, Bechtold ML. Ursodeoxycholic acid in patients with ulcerative colitis and primary sclerosing cholangitis for prevention of colon cancer: a meta-analysis. Indian J Gastroenterol. 2012;31(2):69-74.

33. Hommes DW, Erkelens W, Ponsioen C, Stokkers P, Rauws E, van der Spek M, ten Kate F, et al. A double-blind, placebo-controlled, randomized study of infliximab in primary sclerosing cholangitis. J Clin Gastroenterol. 2008;42(5):522-526.

34. Angulo P, Batts KP, Jorgensen RA, LaRusso NA, Lindor $\mathrm{KD}$. Oral budesonide in the treatment of primary sclerosing cholangitis. Am J Gastroenterol. 2000;95(9):23332337.

35. Goode EC, Rushbrook SM. A review of the medical treatment of primary sclerosing cholangitis in the 21 st century. Ther Adv Chronic Dis. 2016;7(1):68-85.

36. Graziadei IW, Wiesner RH, Marotta PJ, Porayko MK, Hay JE, Charlton MR, Poterucha JJ, et al. Long-term results of patients undergoing liver transplantation for primary sclerosing cholangitis. Hepatology. 1999;30(5):1121-1127.

37. Ponsioen CY, Vrouenraets SM, Prawirodirdjo W, Rajaram R, Rauws EA, Mulder CJ, Reitsma JB, et al. Natural history of primary sclerosing cholangitis and prognostic value of cholangiography in a Dutch population. Gut. 2002;51(4):562-566.

38. Fevery J, Van Steenbergen W, Van Pelt J, Laleman W, Hoffman I, Geboes K, Vermeire S, et al. Patients with large-duct primary sclerosing cholangitis and Crohn's disease have a better outcome than those with ulcerative colitis, or without IBD. Aliment Pharmacol Ther. 2016;43(5):612-620.

39. Kim WR, Therneau TM, Wiesner RH, Poterucha JJ, Benson JT, Malinchoc M, LaRusso NF, et al. A revised natural history model for primary sclerosing cholangitis. Mayo Clin Proc. 2000;75(7):688-694.

40. Chapman R, Fevery J, Kalloo A, Nagorney DM, Boberg KM, Shneider B, Gores GJ, et al. Diagnosis and management of primary sclerosing cholangitis. Hepatology. 
2010;51(2):660-678.

41. Bjornsson E, Boberg KM, Cullen S, Fleming K, Clausen OP, Fausa O, Schrumpf E, et al. Patients with small duct primary sclerosing cholangitis have a favourable long term prognosis. Gut. 2002;51(5):731-735.

42. Halliday JS, Djordjevic J, Lust M, Culver EL, Braden B, Travis SP, Chapman RW. A unique clinical phenotype of primary sclerosing cholangitis associated with Crohn's disease. J Crohns Colitis. 2012;6(2):174-181.

43. Bjornsson E, Olsson R, Bergquist A, Lindgren S, Braden $\mathrm{B}$, Chapman RW, Boberg KM, et al. The natural history of small-duct primary sclerosing cholangitis. Gastroenterology. 2008;134(4):975-980.

44. Saich R, Chapman R. Primary sclerosing cholangitis, autoimmune hepatitis and overlap syndromes in inflammatory bowel disease. World J Gastroenterol. 2008;14(3):331337.

45. Floreani A, Rizzotto ER, Ferrara F, Carderi I, Caroli D, Blasone L, Baldo V. Clinical course and outcome of autoimmune hepatitis/primary sclerosing cholangitis overlap syndrome. Am J Gastroenterol. 2005;100(7):1516-1522.

46. Bjornsson E, Chari ST, Smyrk TC, Lindor K. Immunoglobulin G4 associated cholangitis: description of an emerging clinical entity based on review of the literature. Hepatology. 2007;45(6):1547-1554.

47. Mendes FD, Jorgensen R, Keach J, Katzmann JA, Smyrk $\mathrm{T}$, Donlinger J, Chari S, et al. Elevated serum IgG4 concentration in patients with primary sclerosing cholangitis. Am J Gastroenterol. 2006;101(9):2070-2075.

48. Kalaitzakis E, Levy M, Kamisawa T, Johnson GJ, Baron TH, Topazian MD, Takahashi N, et al. Endoscopic retrograde cholangiography does not reliably distinguish IgG4-associated cholangitis from primary sclerosing cholangitis or cholangiocarcinoma. Clin Gastroenterol Hepatol. 2011;9(9):800-803 e802.

49. Dastis SN, Latinne D, Sempoux C, Geubel AP. Ulcerative colitis associated with IgG4 cholangitis: similar features in two HLA identical siblings. J Hepatol. 2009;51(3):601605.

50. Navaneethan U, Liu X, Bennett AE, Walsh RM, Venkatesh PG, Shen B. IgG4-associated ampullitis and cholangiopathy in Crohn's disease. J Crohns Colitis. 2011;5(5):451456.

51. Ghazale A, Chari ST, Zhang L, Smyrk TC, Takahashi N, Levy MJ, Topazian MD, et al. Immunoglobulin G4associated cholangitis: clinical profile and response to therapy. Gastroenterology. 2008;134(3):706-715.

52. Culver EL, Chapman RW. Systematic review: management options for primary sclerosing cholangitis and its variant forms - IgG4-associated cholangitis and overlap with autoimmune hepatitis. Aliment Pharmacol Ther. 2011;33(12):1273-1291.

53. Zhang FM, Xu CF, Shan GD, Chen HT, Xu GQ. Is gallstone disease associated with inflammatory bowel diseases? A meta-analysis. J Dig Dis. 2015;16(11):634-641.

54. Gizard E, Ford AC, Bronowicki JP, Peyrin-Biroulet L. Systematic review: The epidemiology of the hepatobiliary manifestations in patients with inflammatory bowel disease. Aliment Pharmacol Ther. 2014;40(1):3-15.
55. Parente F, Pastore L, Bargiggia S, Cucino C, Greco S, Molteni M, Ardizzone S, et al. Incidence and risk factors for gallstones in patients with inflammatory bowel disease: a large case-control study. Hepatology. 2007;45(5):12671274.

56. Maurer P, Haag K, Roth M, Kuder C, Scholmerich J. No evidence for abnormal gallbladder emptying in Crohn's disease. Hepatogastroenterology. 1996;43(10):807-812.

57. Mibu R, Makino I, Chijiiwa K. Gallstones and their composition in patients with ileoanal anastomosis. J Gastroenterol. 1995;30(3):413-415.

58. Lapidus A, Einarsson C. Bile composition in patients with ileal resection due to Crohn's disease. Inflamm Bowel Dis. 1998;4(2):89-94.

59. Navaneethan U, Choure A, Venkatesh PG, Hammel J, Lin J, Goldblum JR, Manilich E, et al. Presence of concomitant inflammatory bowel disease is associated with an increased risk of postcholecystectomy complications. Inflamm Bowel Dis. 2012;18(9):1682-1688.

60. Chew SS, Ngo TQ, Douglas PR, Newstead GL, Selby W, Solomon MJ. Cholecystectomy in patients with Crohn's ileitis. Dis Colon Rectum. 2003;46(11):1484-1488.

61. Chalasani N, Younossi Z, Lavine JE, Diehl AM, Brunt EM, Cusi K, Charlton M, et al. The diagnosis and management of non-alcoholic fatty liver disease: Practice guideline by the American Association for the Study of Liver Diseases, American College of Gastroenterology, and the American Gastroenterological Association. Am J Gastroenterol. 2012;107(6):811-826.

62. Rojas-Feria M, Castro M, Suarez E, Ampuero J, Romero-Gomez M. Hepatobiliary manifestations in inflammatory bowel disease: the gut, the drugs and the liver. World J Gastroenterol. 2013;19(42):7327-7340.

63. Bargiggia S, Maconi G, Elli M, Molteni P, Ardizzone S, Parente F, Todaro I, et al. Sonographic prevalence of liver steatosis and biliary tract stones in patients with inflammatory bowel disease: study of 511 subjects at a single center. J Clin Gastroenterol. 2003;36(5):417-420.

64. Li Z, Yang S, Lin H, Huang J, Watkins PA, Moser AB, Desimone $\mathrm{C}$, et al. Probiotics and antibodies to TNF inhibit inflammatory activity and improve nonalcoholic fatty liver disease. Hepatology. 2003;37(2):343-350.

65. Barbuio R, Milanski M, Bertolo MB, Saad MJ, Velloso LA. Infliximab reverses steatosis and improves insulin signal transduction in liver of rats fed a high-fat diet. J Endocrinol. 2007;194(3):539-550.

66. Sourianarayanane A, Garg G, Smith TH, Butt MI, McCullough AJ, Shen B. Risk factors of non-alcoholic fatty liver disease in patients with inflammatory bowel disease. J Crohns Colitis. 2013;7(8):e279-285.

67. Mir-Madjlessi SH, McHenry MC, Farmer RG. Liver abscess in Crohn's disease. Report of four cases and review of the literature. Gastroenterology. 1986;91(4):987-993.

68. Lubbert C, Wiegand J, Karlas T. Therapy of Liver Abscesses. Viszeralmedizin. 2014;30(5):334-341.

69. Lin JN, Lin CL, Lin MC, Lai CH, Lin HH, Kao CH. Pyogenic liver abscess in patients with inflammatory bowel disease: a nationwide cohort study. Liver Int. 2016;36(1):136-144. 
70. van Bokhoven MM, Drenth JP, Nagengast FM. [Liver abscesses as a complication of Crohn's disease]. Ned Tijdschr Geneeskd. 2005;149(28):1584-1587.

71. Rickes S, von Arnim U, Peitz U, Ebert M, Monkemuller $\mathrm{K}$, Malfertheiner P. [Sonographic diagnosis of a liver abscess caused by an enterohepatic fistula in a patient with Crohn's disease]. Ultraschall Med. 2006;27(6):572-576.

72. Flamm SL. Granulomatous liver disease. Clin Liver Dis. 2012;16(2):387-396.

73. Navaneethan U, Shen B. Hepatopancreatobiliary manifestations and complications associated with inflammatory bowel disease. Inflamm Bowel Dis. 2010;16(9):15981619.

74. Saubermann LJ, Deneau M, Falcone RA, Murray KF, Ali S, Kohli R, Ekong UD, et al. Hepatic issues and complications associated with inflammatory bowel disease: a clinical report from the NASPGHAN inflammatory bowel disease and hepatology committees. J Pediatr Gastroenterol Nutr. 2017;64(4):639-652.

75. Braun M, Fraser GM, Kunin M, Salamon F, Tur-Kaspa R. Mesalamine-induced granulomatous hepatitis. Am J Gastroenterol. 1999;94(7):1973-1974.

76. Namias A, Bhalotra R, Donowitz M. Reversible sulfasalazine-induced granulomatous hepatitis. J Clin Gastroenterol. 1981;3(2):193-198.

77. Barrera L, Alvarez J, Tapias M, Idrovo V, Lopez R. Granulomatous hepatitis secondary to histoplasma infection after treatment with infliximab. Case Reports Hepatol. 2013;2013:807537.

78. Meyers S, Janowitz HD, Gumaste VV, Abramson RG, Berman LJ, Venkataseshan VS, Dickman SH. Colchicine therapy of the renal amyloidosis of ulcerative colitis. Gastroenterology. 1988;94(6):1503-1507.

79. Serra I, Oller B, Manosa M, Naves JE, Zabana Y, Cabre E, Domenech E. Systemic amyloidosis in inflammatory bowel disease: retrospective study on its prevalence, clinical presentation, and outcome. J Crohns Colitis. 2010;4(3):269-274.

80. Gottenberg JE, Merle-Vincent F, Bentaberry F, Allanore Y, Berenbaum F, Fautrel B, Combe B, et al. Anti-tumor necrosis factor alpha therapy in fifteen patients with AA amyloidosis secondary to inflammatory arthritides: a followup report of tolerability and efficacy. Arthritis Rheum. 2003;48(7):2019-2024.

81. Lindor KD, Gershwin ME, Poupon R, Kaplan M, Bergasa NV, Heathcote EJ, American Association for Study of Liver D. Primary biliary cirrhosis. Hepatology. 2009;50(1):291-308.

82. Koulentaki M, Koutroubakis IE, Petinaki E, Tzardi M, Oekonomaki H, Mouzas I, Kouroumalis EA. Ulcerative colitis associated with primary biliary cirrhosis. Dig Dis Sci. 1999;44(10):1953-1956.

83. Xiao WB, Liu YL. Primary biliary cirrhosis and ulcerative colitis: a case report and review of literature. World J Gastroenterol. 2003;9(4):878-880.

84. Dacha S, Devidi M, Osmundson E. Budd-Chiari syndrome in a patient with ulcerative colitis and no inherited coagulopathy. World J Hepatol. 2011;3(6):164-169.

85. Talbot RW, Heppell J, Dozois RR, Beart RW, Jr. Vascular complications of inflammatory bowel disease. Mayo Clin Proc. 1986;61(2):140-145.

86. Maconi G, Bolzacchini E, Dell'Era A, Russo U, Ardizzone S, de Franchis R. Portal vein thrombosis in inflammatory bowel diseases: a single-center case series. J Crohns Colitis. 2012;6(3):362-367.

87. Miehsler W, Reinisch W, Valic E, Osterode W, Tillinger W, Feichtenschlager T, Grisar J, et al. Is inflammatory bowel disease an independent and disease specific risk factor for thromboembolism? Gut. 2004;53(4):542-548.

88. Landman C, Nahon S, Cosnes J, Bouhnik Y, Brixi-Benmansour H, Bouguen G, Colombel JF, et al. Portomesenteric vein thrombosis in patients with inflammatory bowel disease. Inflamm Bowel Dis. 2013;19(3):582-589.

89. Matsumoto T, Yamasaki S, Arakawa A, Abe K, Abe H, Kon K, Kobayashi S, et al. Exposure to a high total dosage of glucocorticoids produces non-alcoholic steatohepatits. Pathol Int. 2007;57(6):388-389.

90. Marinos G, Riley J, Painter DM, McCaughan GW. Sulfasalazine-induced fulminant hepatic failure. J Clin Gastroenterol. 1992;14(2):132-135.

91. Loftus EV, Jr., Kane SV, Bjorkman D. Systematic review: short-term adverse effects of 5-aminosalicylic acid agents in the treatment of ulcerative colitis. Aliment Pharmacol Ther. 2004;19(2):179-189.

92. Ransford RA, Langman MJ. Sulphasalazine and mesalazine: serious adverse reactions re-evaluated on the basis of suspected adverse reaction reports to the Committee on Safety of Medicines. Gut. 2002;51(4):536-539.

93. Kremer JM. Liver toxicity does not have to follow methotrexate therapy of patients with rheumatoid arthritis. Am J Gastroenterol. 1997;92(2):194-196.

94. Khan N, Abbas AM, Whang N, Balart LA, Bazzano LA, Kelly TN. Incidence of liver toxicity in inflammatory bowel disease patients treated with methotrexate: a meta-analysis of clinical trials. Inflamm Bowel Dis. 2012;18(2):359-367.

95. Prey S, Paul C. Effect of folic or folinic acid supplementation on methotrexate-associated safety and efficacy in inflammatory disease: a systematic review. Br J Dermatol. 2009;160(3):622-628.

96. Valentino PL, Church PC, Shah PS, Beyene J, Griffiths AM, Feldman BM, Kamath BM. Hepatotoxicity caused by methotrexate therapy in children with inflammatory bowel disease: a systematic review and meta-analysis. Inflamm Bowel Dis. 2014;20(1):47-59.

97. Almeyda J, Baker H, Levene GM, Barnardo D, Landells JW. Methotrexate, alcohol, and liver damage. Br Med J. 1971;2(5754):167.

98. Schmajuk G, Miao Y, Yazdany J, Boscardin WJ, Daikh DI, Steinman MA. Identification of risk factors for elevated transaminases in methotrexate users through an electronic health record. Arthritis Care Res (Hoboken). 2014;66(8):1159-1166.

99. Tran-Minh ML, Sousa P, Maillet M, Allez M, Gornet JM. Hepatic complications induced by immunosuppressants and biologics in inflammatory bowel disease. World J Hepatol. 2017;9(13):613-626.

100. Calabrese E, Hanauer SB. Assessment of non-cirrhotic 
portal hypertension associated with thiopurine therapy in inflammatory bowel disease. J Crohns Colitis. 2011;5(1):48-53.

101. Goldberg R, Irving PM. Toxicity and response to thiopurines in patients with inflammatory bowel disease. Expert Rev Gastroenterol Hepatol. 2015;9(7):891-900.

102. Gisbert JP, Gonzalez-Lama Y, Mate J. Thiopurine-induced liver injury in patients with inflammatory bowel disease: a systematic review. Am J Gastroenterol. 2007;102(7):1518-1527.

103. Chaparro M, Ordas I, Cabre E, Garcia-Sanchez V, Bastida G, Penalva M, Gomollon F, et al. Safety of thiopurine therapy in inflammatory bowel disease: long-term follow-up study of 3931 patients. Inflamm Bowel Dis. 2013;19(7):1404-1410.

104. Dong XW, Zheng Q, Zhu MM, Tong JL, Ran ZH. Thiopurine S-methyltransferase polymorphisms and thiopurine toxicity in treatment of inflammatory bowel disease. World J Gastroenterol. 2010;16(25):3187-3195.

105. Vernier-Massouille G, Cosnes J, Lemann M, Marteau P, Reinisch W, Laharie D, Cadiot G, et al. Nodular regenerative hyperplasia in patients with inflammatory bowel disease treated with azathioprine. Gut. 2007;56(10):14041409.

106. Ferlitsch A, Teml A, Reinisch W, Ulbrich G, Wrba F, Homoncik M, Gangl A, et al. 6-thioguanine associated nodular regenerative hyperplasia in patients with inflammatory bowel disease may induce portal hypertension. Am J Gastroenterol. 2007;102(11):2495-2503.

107. Seinen ML, van Asseldonk DP, de Boer NK, Bouma G, van Nieuwkerk CM, Mulder CJ, Bloemena E, et al. Nodular regenerative hyperplasia of the liver in patients with IBD treated with allopurinol-thiopurine combination therapy. Inflamm Bowel Dis. 2017;23(3):448-452.

108. Holtmann M, Schreiner O, Kohler H, Denzer U, Neurath M, Galle PR, Hohler T. Veno-occlusive disease (VOD) in Crohn's disease (CD) treated with azathioprine. Dig Dis Sci. 2003;48(8):1503-1505.

109. Russmann S, Zimmermann A, Krahenbuhl S, Kern B, Reichen J. Veno-occlusive disease, nodular regenerative hyperplasia and hepatocellular carcinoma after azathioprine treatment in a patient with ulcerative colitis. Eur J Gastroenterol Hepatol. 2001;13(3):287-290.

110. Shelton E, Chaudrey K, Sauk J, Khalili H, Masia R, Nguyen DD, Yajnik V, et al. New onset idiosyncratic liver enzyme elevations with biological therapy in inflammatory bowel disease. Aliment Pharmacol Ther. 2015;41(10):972-979.

111. de Vries HS, de Heij T, Roelofs HM, te Morsche RH, Peters WH, de Jong DJ. Infliximab exerts no direct hepatotoxic effect on HepG2 cells in vitro. Dig Dis Sci. 2012;57(6):1604-1608.

112. Miehsler W, Novacek G, Wenzl H, Vogelsang H, Knoflach P, Kaser A, Dejaco C, et al. A decade of infliximab: The Austrian evidence based consensus on the safe use of infliximab in inflammatory bowel disease. J Crohns Colitis. 2010;4(3):221-256.

113. Ghabril M, Bonkovsky HL, Kum C, Davern T, Hayashi $\mathrm{PH}$, Kleiner DE, Serrano J, et al. Liver injury from tumor necrosis factor-alpha antagonists: analysis of thirty-four cases. Clin Gastroenterol Hepatol. 2013;11(5):558-564 e553.

114. Kay J, Matteson EL, Dasgupta B, Nash P, Durez P, Hall $\mathrm{S}$, Hsia EC, et al. Golimumab in patients with active rheumatoid arthritis despite treatment with methotrexate: a randomized, double-blind, placebo-controlled, doseranging study. Arthritis Rheum. 2008;58(4):964-975.

115. Inman RD, Davis JC, Jr., Heijde D, Diekman L, Sieper J, Kim SI, Mack M, et al. Efficacy and safety of golimumab in patients with ankylosing spondylitis: results of a randomized, double-blind, placebo-controlled, phase III trial. Arthritis Rheum. 2008;58(11):3402-3412.

116. Sandborn WJ, Feagan BG, Rutgeerts P, Hanauer S, Colombel JF, Sands BE, Lukas M, et al. Vedolizumab as induction and maintenance therapy for Crohn's disease. N Engl J Med. 2013;369(8):711-721.

117. Feagan BG, Rutgeerts P, Sands BE, Hanauer S, Colombel JF, Sandborn WJ, Van Assche G, et al. Vedolizumab as induction and maintenance therapy for ulcerative colitis. N Engl J Med. 2013;369(8):699-710.

118. Thai A, Prindiville T. Hepatosplenic T-cell lymphoma and inflammatory bowel disease. J Crohns Colitis. 2010;4(5):511-522.

119. Kotlyar DS, Osterman MT, Diamond RH, Porter D, Blonski WC, Wasik M, Sampat S, et al. A systematic review of factors that contribute to hepatosplenic T-cell lymphoma in patients with inflammatory bowel disease. Clin Gastroenterol Hepatol. 2011;9(1):36-41 e31.

120. Loras C, Saro C, Gonzalez-Huix F, Minguez M, Merino O, Gisbert JP, Barrio J, et al. Prevalence and factors related to hepatitis $\mathrm{B}$ and $\mathrm{C}$ in inflammatory bowel disease patients in Spain: a nationwide, multicenter study. Am J Gastroenterol. 2009;104(1):57-63.

121. Perrillo RP. Acute flares in chronic hepatitis B: the natural and unnatural history of an immunologically mediated liver disease. Gastroenterology. 2001;120(4):1009-1022.

122. Loras C, Gisbert JP, Minguez M, Merino O, Bujanda L, Saro C, Domenech E, et al. Liver dysfunction related to hepatitis $\mathrm{B}$ and $\mathrm{C}$ in patients with inflammatory bowel disease treated with immunosuppressive therapy. Gut. 2010;59(10):1340-1346.

123. Rahier JF, Ben-Horin S, Chowers Y, Conlon C, De Munter P, D'Haens G, Domenech E, et al. European evidence-based Consensus on the prevention, diagnosis and management of opportunistic infections in inflammatory bowel disease. J Crohns Colitis. 2009;3(2):47-91.

124. Vida Perez L, Gomez Camacho F, Garcia Sanchez V, Iglesias Flores EM, Castillo Molina L, Cerezo Ruiz A, Casais Juanena L, et al. [Adequate rate of response to hepatitis $B$ virus vaccination in patients with inflammatory bowel disease]. Med Clin (Barc). 2009;132(9):331-335.

125. Sempere L, Almenta I, Barrenengoa J, Gutierrez A, Villanueva CO, de-Madaria E, Garcia V, et al. Factors predicting response to hepatitis $\mathrm{B}$ vaccination in patients with inflammatory bowel disease. Vaccine. 2013;31(30):30653071.

126. Gisbert JP, Villagrasa JR, Rodriguez-Nogueiras A, Chaparro M. Kinetics of anti-hepatitis B surface antigen titers 
after hepatitis B vaccination in patients with inflammatory bowel disease. Inflamm Bowel Dis. 2013;19(3):554558.

127. Allen AM, Kim WR, Larson J, Loftus EV, Jr. Efficacy and safety of treatment of hepatitis $\mathrm{C}$ in patients with inflammatory bowel disease. Clin Gastroenterol Hepatol.
2013;11(12):1655-1660 e11651.

128. Lin MV, Blonski W, Buchner AM, Reddy KR, Lichtenstein GR. The influence of anti-TNF therapy on the course of chronic hepatitis $\mathrm{C}$ virus infection in patients with inflammatory bowel disease. Dig Dis Sci. 2013;58(4):11491156. 